\title{
Research on optimization of single well testing workload and efficiency
}

\author{
Pan Hong ${ }^{1}$ \\ ${ }^{1}$ The eighth oil production plant of daqing oil field, Daqing, Heilongjiang, China
}

\begin{abstract}
With the enlargement of production scale and the increase of survey and adjustment work, the mismatch between test requirement and test capability becomes more and more serious. In order to further control the test cost and improve the efficiency of survey and adjustment, according to the characteristics of the peripheral oil reservoirs and sections, differential management of survey and adjustment cycle and effective methods of matching injection points are actively carried out, on the basis of satisfying the development requirements and smooth operation of various indexes, solve the mismatch between test requirements and test capabilities. By analyzing the use cycle of test data under different conditions, the type of wells with extended use cycle is determined, which can effectively reduce the need of test work under the condition that the separate layer water injection is qualified. The distribution rules of different sizes of nozzles are statistically analyzed, and the selection rules of nozzles in special layers are made clear in advance to improve the debugging efficiency of injection allocation points.
\end{abstract}

\section{Introduction}

In recent years, on the premise of the decrease of drilling scale, the production is increasing year by year, and the quality of water injection is required to be improved continuously. In order to push forward the water injection work in the oilfield of "enough water injection, good water injection, fine water injection and effective water injection", it is required that the passing rate of testing in separate water injection wells should reach over $98 \%$, and the passing rate of separate water injection should keep above $90 \%$ and run smoothly, the separate layer adjustment technique of water injection well is the main method to measure and adjust the water absorption of formation, and the main factor that affects the separate layer water injection qualified rate decides the operation of separate layer water injection qualified rate index[1].

The peripheral oilfields have relatively poor reservoir development, great difference of water absorption between layers, low injection rate of interval, difficulty of layer-by-layer debugging, and great difference of test data using cycle. The testing workload is expected to reach 5,259 wells, which is 603 wells more than last year. It is difficult to complete the annual debugging plan when the testing team can not increase year by year. In order to ensure the high-level operation of water injection index and solve the contradiction between the demand of survey and regulation and the ability of survey and regulation, it is urgent to extend the period of qualified well logging and regulation and improve the efficiency of survey and regulation. At present, the uniform test cycle is applied to test data, which makes part of test data debug under qualified condition, and produces repeated workload. Although there are some theoretical formulas to determine the nozzle in advance, in the course of testing, the theoretical formula of water distribution nozzle as a basis is not feasible because of the factors such as the contradiction between layers, water quality, sand, scale, oil and so on, at present, there is no good empirical or theoretical formula for predicting nozzle size in advance, and the efficiency of measuring and allocating injection points can be greatly improved by determining the application range of nozzle size under specific parameters.

\section{Principle of layering survey and adjustment technology}

At present, the main debugging technology of our factory is the non-collecting ultrasonic flowmeter, which is used to measure the stratified flow by hanging in the tubing. Before the layer-by-layer debugging, the current real water injection rate should be checked and matched with the flowmeter[2]. When the layer-by-layer flow rate of the check and match does not meet the requirement of the layer-by-layer injection rate, the plug should be put into the ground, after changing the size of the nozzle, it is put into the bottom of the well by the dropper, and then the flowmeter is put into the well to be tested. There are many kinds of ultrasonic flow meters, which can be divided into velocity method, phase difference method, correlation method, Doppler effect method[3], etc. . The

Corresponding author's e-mail: phcy8@petrochina.com.cn 
principle of ultrasonic testing instrument is based on the different speed of sound wave in different media, the speed is high when it travels in the same direction as the fluid, and the speed is low when it travels in the opposite direction, according to the time difference of receiving sound wave within a fixed distance, the method for finding the velocity is called the propagation time method. That is, after the flowmeter goes down into the well, it sends out a set of opposite ultrasonic waves in the fluid and receives them separately at the two ends of the instrument, the instantaneous flow rate of injection well can be calculated by time difference. The ultrasonic flowmeter has the advantages of no moving parts, no interference to fluid velocity, no pressure loss, high measurement accuracy and wide testing range[4]. The ultrasonic flowmeter is a non-collecting flow measuring instrument, which does not touch the fluid in the course of testing. It can be used for non-stopping well testing by using the ultrasonic flowmeter.

\section{Improve the effectiveness of health measures}

Table1. Classified statistical table of debugging well

\begin{tabular}{|c|c|c|c|c|c|c|c|}
\hline $\begin{array}{c}\text { Commissioning } \\
\text { reason }\end{array}$ & data due & $\begin{array}{c}\text { pressure } \\
\text { chang }\end{array}$ & new well & $\begin{array}{c}\text { program } \\
\text { stmen }\end{array}$ & measures & $\begin{array}{c}\text { operation } \\
\text { s }\end{array}$ & total \\
\hline $\begin{array}{c}\text { Active } \\
\text { debugging }\end{array}$ & 2478 & 673 & & & & & 3151 \\
\hline $\begin{array}{c}\text { passive } \\
\text { ebugging }\end{array}$ & 2478 & 673 & 618 & 701 & 55 & 131 & 4656 \\
\hline total & 24781 & 55 & 1305 \\
\hline
\end{tabular}

According to the Distribution Law of adjustment wells within the range of 0.4-0.4 MPA, the proportion of adjustment wells with due date in oil1, oil2, oil3 andoil4

\subsection{Optimizing the adjustment period of single well logging}

In recent years, with the increase of the number of water injection wells and the requirement of fine water injection management, the work load of layer adjustment has increased year by year. In order to further control the cost of testing and reduce the workload of testing and adjustment, the differential management of single well testing cycle is emphasized. The debugging reason is divided into active adjustment and passive adjustment, in which the passive adjustment well is adjusted because the development needs, and the testing period is uncontrollable, active adjustment well is due to the normal use of test data or the use of data in the process of water-free phenomenon, can be appropriate to extend the use of qualified data cycle, reduce the need for testing. The reason for debugging is that in the 3151 wells with variable pressure and data due, the 1487 wells with two consecutive test oil pressure fluctuations in the range of-0.4-0.4 MPA account for $47.2 \%$ of the debugging wells, of which the data due accounts for $90.9 \%$.

Table2. Distribs

\begin{tabular}{|c|c|c|c|c|c|c|c|}
\hline Table2. Distribution Law of divided oilfield in debugging well \\
\hline pressure change & 88 & 17 & 2 & 7 & 4 & 18 & 136 \\
\hline data due & 709 & 49 & 43 & 85 & 199 & 266 & 1351 \\
\hline subtotal & 797 & 66 & 45 & 92 & 203 & 284 & 1487 \\
\hline $\begin{array}{c}\text { Pressure change } \\
\text { ratio }\end{array}$ & 11.0 & 25.8 & 4.4 & 7.6 & 2.0 & 6.3 & 9.1 \\
\hline data due ratio & 89.0 & 74.2 & 95.6 & 92.4 & 98.0 & 93.7 & 90.9 \\
\hline
\end{tabular}

40 test wells were followed, and the test data were used for 5 and 6 months to check and match, the check and match were unqualified or the pressure was over \pm 0.4 MPA. Using the test data for 4,5 and 6 months, the oilfields is more than $90 \%$, and the proportion of adjustment wells with due date in oil 2 oilfield is the smallest.

oilfield in debugging well

pass rates of interval water injection are $97.5 \%, 93.5 \%$ and $91.7 \%$ respectively. Therefore, the test period is extended to 6 months in two consecutive test wells with oil pressure fluctuation in the range of-0.4-0.4 MPA, on 
the premise of meeting the development target, the test workload is effectively reduced.

\subsection{Determine the application scope of conventional water nozzle in advance}

The statistics of 4767 layers (excluding single-layer injection well and single-layer stop-injection layer) showed that the size of water nozzle mainly concentrated in 4-6mm, quantitative and empty net, accounting for $81.9 \%$ of total applied water nozzle. In order to count the application characteristics of the sizes of $4-6 \mathrm{~mm}$ and open water nozzle, the multi-layer wells which used edge

Table3. Application statistics of different size nozzle in different layers

\begin{tabular}{|c|c|c|c|c|c|c|}
\hline Project & Skews I & Skews II & SkewsIII & SkewsIV & SkewsVI & total \\
\hline Empty Net(s) & 1370 & 611 & 153 & 26 & 3 & 2163 \\
\hline 4-6mm(s) & 191 & 738 & 254 & 12 & 0 & 1195 \\
\hline quantitative(s) & 100 & 310 & 122 & 12 & 0 & 544 \\
\hline other (s) & 241 & 235 & 163 & 33 & 0 & 672 \\
\hline total(s) & 1902 & 1894 & 692 & 83 & 3 & 4574 \\
\hline empty net(s) & 72.0 & 32.3 & 22.1 & 31.3 & 100 & 47.3 \\
\hline 4-6mm (\%) & 10.0 & 39.0 & 36.7 & 14.5 & 0.0 & 26.1 \\
\hline total (\%) & 82.1 & 71.2 & 58.8 & 45.8 & 100 & 73.4 \\
\hline
\end{tabular}

According to the application situation of different size water nozzle in different layers in oil field, the application of water nozzle in empty network layer, layers I and IV of oil3, layers I of oil4, layers I of oil5, layers I and IV of oil6 and layers I and II of oil3 have higher application ratio, the application ratio of Layer III in Sheng oilfield and Layer II in oil4 is high. There are 2692 layers with the frequency of more than $60 \%$, accounting for $58.9 \%$ of the total debugging layers.

In order to count the effect of Distribution Law of water nozzles on debugging efficiency, 20 wells in oil3 were selected randomly and compared before and after testing, a total of 12 water nozzles were replaced, among them, there are 8 related wells in partial I and III layers (4 wells in partial I layer and 6 wells in partial III layer), under the guidance of two kinds of nozzles with high probability in partial I and III layers, four wells were successfully debugged directly after one time fishing, the debugging time of injection allocation point is effectively reduced, the average single well debugging time is reduced by 1.36 hours, and the testing efficiency is improved by 16 percentage points

\section{Conclusion}

Based on the results and discussions presented above, the conclusions are obtained as below: measurement and adjustment technique were not included in the statistical range. In the statistics of water nozzles used in stratified wells, the proportion of water nozzles used in empty network is $93.7 \%$, the proportion of water nozzles used in $4-6 \mathrm{~mm}$ is $52.4 \%$, and the proportion of water nozzles used in interval interval is the highest, the proportion of partial I and partial VI is $72.0 \%$ and $100 \%$, respectively, partial 2 and partial 4 have higher proportion of empty net, partial 2 and partial 3 have higher proportion of 4-6 mm nozzle, $39.0 \%$ and $36.7 \%$ respectively.
1. Differential management of test cycle and improvement of debugging efficiency are the main methods to solve the problem of mismatch between test requirement and test capability.

2. Extending the testing period from-0.4-0.4 MPA to 6 months can effectively reduce the testing workload while meeting the development requirements.

3 . The frequency of empty net and 4-6mm nozzle is over $60 \%$ of adjustment range in advance, and the testing efficiency is expected to be improved by 16 percentage points.

\section{References}

1. measurement and adjustment integrated subdivided injection well stratified flow test technology petroleum geology and development of Daqing, 2000, 19(3) : 38 411

2. Hu Bozhong, editor-in-chief, 1 selected papers on oil production engineering in Daqing Field (1995 1997)[ C ]1 BEIJING: Petroleum Industry Press, 1997:51 $\sim 551$

3. Mass asymmetry and tricyclic wobble motion assessment using automated launch video analysis[J]. Ryan DECKER, Joseph DONINI, William GARDNER, Jobin JOHN, Walter 
KOENIG. Defence Technology , 2016,(02)

4. Determining the impact of rectangular grain aspect ratio on tortuosity-porosity correlations of two-dimensional stochastically generated porous media[J].A.Ebrahimi Khabbazi, J.Hinebaugh, A.Bazylak. Science Bulletin , 2016,(08) 